\title{
Oxidant-antioxidant Status and Lipid Profile in the Hypertensive Patients.
}

\author{
Maharjan BR, ${ }^{1}$ Jha JC, ${ }^{2}$ Vishwanath $\mathrm{P},{ }^{2}$ Alurkar VM, ${ }^{3}$ Singh PP2 \\ ${ }^{1}$ Department of Biochemistry, Kathmandu University of Medical Sciences, Chaukot, Kavre, Nepal, ${ }^{2}$ Department of \\ Biochemistry, MCOMS, '3epartment of Medicine, Manipal College of Medical Sciences, Deep Heights, Pokhara, Nepal
}

\section{ABSTRACT}

\begin{abstract}
Background: Hypertension is associated with an elevation of ROS and frequently also with an impairment of endogenous antioxidant mechanisms. Increased level of serum cholesterol, TG, VLDL has been observed in patients with hypertension. It has been shown that oxidized lipoprotein inactivates NO and aggravates hypertension. This study intends to know the association of oxidative stress and lipid profile with hypertensive patients of the Western Nepal.

Methods: Our study group comprised of 32 confirmed cases of HTN. Inclusion criteria included the patients with blood pressure $\geq 140 / 90 \mathrm{~mm}$ of $\mathrm{Hg}$. Patients with secondary hypertension, past history of stroke, coronary artery disease (CAD), myocardial infarction, and peripheral vascular disease and diabetes mellitus were excluded. Serum lipid profile, plasma thiobarbituric acid reactive substances (PTBARS), plasma total antioxidant activity (TAA) and urinary thiobarbituric acid reactive substances (UTBARS) were estimated in these patients by standard procedures and the values were compared with 30 age, sex and socioeconomically matched normal healthy control subjects.

Results: TBARS levels and Lipid profile were significantly raised in HTN patients, but TAA and urinary TBARS levels were comparable to normal subjects. BMI and W/H ratio in patients were comparable to control. Smoking and alcohol did not influence lipid profile, TBARS and TAA.

Conclusion: Lipid profile andTBARS were significantly raised in HTN patients compare to controls. Thus, monitoring lipid level and maintaining oxidative balance in hypertensive patients would be helpful in preventing the diseases associated with hypertension.

Key words: Hypertension, lipid profile, oxidative stress, antioxidant, Nepal.
\end{abstract}

\section{INTRODUCTION}

A study has shown that more than a quarter of the world's adult population, totaling nearly one billion, had hypertension in 2000 , and this population will increase to $29 \%, 1.56$ billion by $2025 .^{1}$ Hypertension is an important risk factor for cardio vascular diseases (CVD). ${ }^{2}$ According to estimates by the WHO 2001, CVD accounts for $29 \%$ of all deaths and $11 \%$ of disease burden in the South-East Asia. ${ }^{3}$ A study conducted in the Eastern Nepal has showed the direct association of dyslipidemia and BMI in hypertensive patients. ${ }^{4}$ However, the study regarding association of oxidative stress and lipid profile in hypertensive patients is rare in Nepal. Lassegue et al (2004) found convincing evidence that reactive oxygen species (ROS) an intrinsic part of the pathology of hypertension. They contribute to the disease through multiple mechanisms, involving the vasculature, heart, kidneys, and central nervous system. ${ }^{5}$ This study observed the status of oxidative stress and lipid profile in hypertensive patients of the Western Nepal. 
An excessive ROS concentration, especially hydroxyl radical, has been found in patients with essential hypertension ${ }^{6}$. According to Harman's theory, oxidative stress is intensified with the process of aging ${ }^{7}$, and in the elderly, this is accompanied by a more common occurrence of primary hypertension ${ }^{6,7}$

Hypercholesterolemia aggravates hypertension by impairing vasodilation and Chin et al found it to be mediated by inactivation of NO by lysolecithin component of Oxidised lipoprotein. ${ }^{8,9}$ Also, it has been shown that the endothelial dysfunction is reverted when dyslipidemia is corrected. ${ }^{10}$

Atherosclerosis is decidedly the major cause of CVD. An important initial event of atherosclerosis is due to the transport of oxidized low density lipoprotein $(0$ LDL) across the endothelium into the artery wall. ${ }^{11}$ ROS mediate various signaling pathways that underlie vascular inflammation in atherogenesis: from the initiation of fatty streak development through lesion progress to ultimate plaque rupture. ${ }^{12}$

Obesity is closely associated with metabolic syndrome including hyperglycemia, dyslipidemia and hypertension ${ }^{13}$. Obesity per se induces systemic oxidative stress and that increased oxidative stress in accumulated fat is, at least in part, the underlying cause of dysregulations of adipocytokines and development of metabolic syndrome. ${ }^{14}$

\section{METHODS}

This study was undertaken in Department of Biochemistry of Manipal Teaching Hospital, Pokhara. The study was approved by the institutional ethical committee. Prior verbal consent was taken from all the subjects participating in the study. Our study group included 32 patients with hypertension (males $=25$ and females=7) and 30 age and sex matched healthy controls (males $=17$ and females=13).

Detailed present and past histories of the patients were collected with the help of pre-test proforma. The Proforma included, name, age, sex, dietary habit (vegetarian/non-vegetarian), family history of disease (if any), smoking habit, drinking habit, socio-economic status, community and occupation. We also measured physical parameters such as waist circumference $(\mathrm{cm})$, hip circumference $(\mathrm{cm})$, height $(\mathrm{m})$ and weight $(\mathrm{Kg})$.

Total 30 participants with age and sex matched, healthy (i.e. not suffering from any a malignancy, known cardiovascular diseases and diabetes) individuals were taken as control. Personal information was gathered from them as stated for patients.
After 12 hours overnight fast, $6 \mathrm{ml}$ of blood was collected from each subject by venipuncture with standard blood collection technique. The separated plasma was used for the analyses of total antioxidant activity (TAA) by ferric reducing antioxidant power assay (FRAP), plasma thiobarbituric acid reactive substances (TBARS) and lipid profile total cholesterol (TC), triglycerides (TG), HDLcholesterol, LDL- cholesterol and VLDL-cholesterol). ${ }^{15-19}$ About $30 \mathrm{ml}$ of urine was collected without preservative for the analysis of urinary TBARS in clean dry container.

Analytical reagents for estimation of TAA and TBARS were purchased from Central Drug House Pvt Ltd., Bombay-Delhi India and fresh reagents were prepared in laboratory prior to estimation. But for lipid profile, we purchased kits from Randox Laboratories Ltd, United Kingdom and processed through semi-autoanalyzer, Microlab-300, Netherland.

Computer software program SPSS version 10.0 was used for the statistical analysis of different biochemical parameters for the interpretation of the result. Data were processed for obtaining ' $p$ ' value of Independent Sample t-test and Pearson Correlation.

\section{RESULT}

Total cholesterol, Triglyceride, VLDL and LDL level were significantly raised in HTN patients when compared to normal subjects (Table 1). About $96.7 \%$ of the normal subjects had total cholesterol $<200 \mathrm{mg} / \mathrm{dl}$ whereas $62.5 \%$ of the HTN patients had TC in this level. Similarly, 93.3\% of the normal subjects and $78.5 \%$ of the HTN patients had LDL-cholesterol level $<130 \mathrm{mg} / \mathrm{dl}$ (safe level). Noticeably $30 \%$ of normal subjects and $29.0 \%$ of the HTN patients had HDL-cholesterol level $<40 \mathrm{mg} / \mathrm{dl}$ (Table 2). We observed positive correlation between TG and TC in normal subjects $(r=0.383, p=0.003)$ as well as in HTN patients $(r=0.487, p=0.005)$ (Table 4$)$.

The plasma TBARS levels in HTN patients were significantly higher than normal subjects $(p<0.001)$ but TAA levels were comparable between two groups (Table 1). Strikingly, there was an inverse relationship between TAA and plasma TBARS in normal subjects $(r=-0.339, p=$ $0.008)$ and also in HTN patients $(r=-0.361, p=0.042)$. No discernible significance was observed in the oxidative stress, TAA and lipid profile in both control and patients when compared on the basis of smoking and drinking habits (Table 4 and 5).

\section{DISCUSSION}

The total cholesterol level was $155 \pm 25 \mathrm{mg} / \mathrm{dl}$ with a range of $112-232 \mathrm{mg} / \mathrm{dl}$. We do not have redefined levels for Nepalese population, but as per WHO and Indian Council of Medical Research recommendations, levels 
Table 1. Independent sample-t test between control and HTN patient.

\begin{tabular}{|lll|}
\hline Parameters & $\begin{array}{l}\text { Control } \\
\text { Mean } \pm \text { SD }\end{array}$ & $\begin{array}{l}\text { HTN } \\
\text { Mean } \pm \text { SD }\end{array}$ \\
\hline Age (years) & $50.80 \pm 14.84$ & $49.63 \pm 16.15$ \\
BMl & $23.65 \pm 3.94$ & $25.17 \pm 3.75$ \\
W/H & $0.94 \pm 0.09$ & $0.96 \pm 0.07$ \\
TC $(\mathrm{mg} / \mathrm{dl})$ & $155 \pm 25$ & $185 \pm 38^{\mathrm{b}}$ \\
TG $(\mathrm{mg} / \mathrm{dl})$ & $123 \pm 36$ & $169 \pm 90{ }^{\mathrm{a}}$ \\
HDL $(\mathrm{mg} / \mathrm{dl})$ & $45 \pm 8$ & $44 \pm 7$ \\
VLDL $(\mathrm{mg} / \mathrm{dl})$ & $25 \pm 7$ & $34 \pm 18{ }^{\mathrm{a}}$ \\
LDL $(\mathrm{mg} / \mathrm{dl})$ & $85 \pm 20$ & $107 \pm 31 \mathrm{~b}$ \\
STAA $(\mu \mathrm{mol} / \mathrm{l})$ & $726 \pm 200$ & $667 \pm 175$ \\
PTBARS $(\mathrm{nmol} / \mathrm{ml})$ & $2.41 \pm 0.61$ & $3.29 \pm 0.83^{c}$ \\
UTBARS $(\mathrm{nmol} / \mathrm{ml})$ & $3.84 \pm 1.63$ & $4.37 \pm 1.91$ \\
\hline
\end{tabular}

Independent sample-t test: $p<0.05=a, p<0.01=b$ and $p<0.001=c$

Table 2. Percentage distribution of control and HTN patients at different ranges of total cholesterol, HDLC and LDL-C

\begin{tabular}{|c|c|c|}
\hline Description & $\begin{array}{c}\text { Control } \\
(30) \\
\text { N (\%) }\end{array}$ & $\begin{array}{l}\text { HTN } \\
(32) \\
N(\%)\end{array}$ \\
\hline \multicolumn{3}{|l|}{ CHOLESTEROL } \\
\hline$\leq 180 \mathrm{mg} / \mathrm{dl}$ & 27 (90.0\%) & 18 (56.2\%) \\
\hline $181-199 \mathrm{mg} / \mathrm{dl}$ & $2(6.7 \%)$ & $2(6.3 \%)$ \\
\hline$<200 \mathrm{mg} / \mathrm{dl}$ & 29 (96.7\%) & 20 (62.5\%) \\
\hline $200-239 \mathrm{mg} / \mathrm{dl}$ & $1(3.3 \%)$ & 9 (28.1\%) \\
\hline$\geq 240 \mathrm{mg} / \mathrm{dl}$ & - & $3(9.4 \%)$ \\
\hline \multicolumn{3}{|l|}{ HDL-C } \\
\hline$<40 \mathrm{mg} / \mathrm{dl}$ & 28 (93.3\%) & 31 (96.9\%) \\
\hline$\geq 60 \mathrm{mg} / \mathrm{dl}$ & $2(6.7 \%)$ & $1(3.12 \%)$ \\
\hline \multicolumn{3}{|l|}{ LDL-C } \\
\hline$<100 \mathrm{mg} / \mathrm{dl}$ & 24 (80\%) & 14 (42.7\%) \\
\hline $100-129 \mathrm{mg} / \mathrm{dl}$ & 4 (13.3\%) & 9 (28.1\%) \\
\hline $130-159 \mathrm{mg} / \mathrm{dl}$ & $4(6.7 \%)$ & $8(25.0 \%)$ \\
\hline $160-189 \mathrm{mg} / \mathrm{dl}$ & - & $1(3.1 \%)$ \\
\hline$\geq 190 \mathrm{mg} / \mathrm{dl}$ & - & - \\
\hline
\end{tabular}

Table 3. Pearson's correlation coefficient of different parameters in controls and DM patients

\begin{tabular}{lllll|}
\hline \multirow{2}{*}{ Parameters } & \multicolumn{2}{c}{ Control } & \multicolumn{2}{c|}{ HTN } \\
& r-value & p-value & r-value & p-value \\
\hline PTBARS vs TAA & -0.339 & $0.008^{\mathrm{b}}$ & -0.361 & 0.070 \\
PTBARS vs TC & 0.030 & 0.821 & -0.313 & $0.008^{\mathrm{b}}$ \\
PTBARS vs TG & -0.075 & 0.571 & -0.537 & $0.005^{\mathrm{b}}$ \\
BMI vs TAA & 0.251 & 0.181 & 0.093 & 0.611 \\
BMI vs PTBARS & -0.225 & 0.232 & -0.106 & 0.565 \\
BMI vs TC & 0.100 & 0.598 & -0.064 & 0.729 \\
BMI vs TG & 0.012 & 0.998 & 0.021 & 0.907 \\
\hline
\end{tabular}

are: desirable $<200 \mathrm{mg} / \mathrm{dl}$, borderline high- 200-240 $\mathrm{mg} / \mathrm{dl}$ and high risk $>240 \mathrm{mg} / \mathrm{dl}^{20}$ The same levels are recommended for western population also. ${ }^{21}$ Accepting these limits for Nepalese also, (96.7\%) had desirable level, (3.3\%) had borderline high level and none were in high risk zone. Similar to the study done by Baral $\mathrm{N}$ et al in the Eastern Nepal, We also observed the significant increase in the TC, TG, LDL, VLDL in hypertension compared to control except HDL which does not show any significant difference. ${ }^{4}$

The plasma TBARS level was significantly raised in patients with HTN compared to controls. The TAA levels in control and HTN were $726 \pm 200 \mu \mathrm{mol} / \mathrm{l}$ and $698 \pm 175$ $\mu \mathrm{mol} / \mathrm{l}$ respectively. The normal level of TAA as per Benzie and Strain (1999) method is in the range of 600$1600 \mu \mathrm{mol} / \mathrm{l} .{ }^{15}$ It can be seen from our result that TAA levels in HTN was normal and not significantly different from controls, yet their PTBARS levels were raised than controls however the urinary TBARS were comparable. The unaltered urinary TBARS level in HTN shows that raised plasma TBARS is due to increased production rather than its compromised excretion.

The relationship between TAA and PTBARS follows inverse relationship. ${ }^{22}$ Our results in normal subject $(r=-0.339, p$ $=0.008)$ and HTN patients $(r=-0.361, p=0.042)$ support this hypothesis. Because of this inverse relationship between oxidative stress and antioxidants, antioxidant therapy has been enthusiastically advocated to balance the relationship. However, several recent evidences have strongly questioned it because unphysiologic oxidative stress is not a ubiquitous phenomenon in all the patients of same disease and in all the diseases. ${ }^{23,24} \mathrm{It}$, therefore, is strongly felt that synthetic antioxidants should not be used therapeutically, unless their in vivo effectiveness in suitable animal models is well proven. 
Table 4. Independent sample-t test between Alcoholics and non-alcoholics

Control

Hypertension

\begin{tabular}{|lcccc|} 
Parameter & $\begin{array}{c}\text { Alcoholic } \\
(\mathrm{N}=11)\end{array}$ & $\begin{array}{c}\text { Non Alcoholic } \\
(\mathrm{N}=19)\end{array}$ & $\begin{array}{c}\text { Alcoholic } \\
(\mathrm{N}=20)\end{array}$ & $\begin{array}{c}\text { Non Alcoholic } \\
(\mathrm{N}=12)\end{array}$ \\
\hline BMl $(\mathrm{Kg} / \mathrm{m} 2)$ & $23.80 \pm 3.21$ & $23.56 \pm 4.39$ & $25.11 \pm 3.28$ & $25.14 \pm 4.51$ \\
W/H & $0.94 \pm 0.07$ & $0.93 \pm 0.10$ & $0.97 \pm 0.07$ & $0.96 \pm 0.07$ \\
TC $(\mathrm{mg} / \mathrm{dl})$ & $150 \pm 23$ & $157 \pm 26$ & $186 \pm 37$ & $182 \pm 38$ \\
TG $(\mathrm{mg} / \mathrm{dl})$ & $131 \pm 39$ & $117 \pm 33$ & $183 \pm 84$ & $143 \pm 87$ \\
HDL $(\mathrm{mg} / \mathrm{dl})$ & $43 \pm 8$ & $45 \pm 7$ & $44 \pm 7$ & $42 \pm 6$ \\
VLDL $(\mathrm{mg} / \mathrm{dl})$ & $26 \pm 7$ & $23 \pm 6$ & $36 \pm 18$ & $30 \pm 17$ \\
LDL $(\mathrm{mg} / \mathrm{dl})$ & $80 \pm 19$ & $88 \pm 20$ & $104 \pm 28$ & $111 \pm 37$ \\
STAA $(\mu \mathrm{mol} / \mathrm{l})$ & $760 \pm 241$ & $706 \pm 174$ & $667 \pm 181$ & $664 \pm 170$ \\
PTBARS $(\mathrm{nmol} / \mathrm{ml})$ & $2.47 \pm 0.57$ & $2.38 \pm 0.65$ & $3.12 \pm 0.85$ & $3.56 \pm 0.79$ \\
UTBARS $(\mathrm{nmol} / \mathrm{ml})$ & $3.89 \pm 1.14$ & $3.80 \pm 1.78$ & $3.80 \pm 1.37$ & $5.33+2.33$ \\
\hline
\end{tabular}

Independent sample-t test: $p<0.05=a, p<0.01=b$ and $p<0.001=c$

Table 5. Independent sample-t test between smokers and non-smokers.

Control

Hypertension

\begin{tabular}{|lcccc|} 
Parameter & $\begin{array}{c}\text { Smoker } \\
(\mathrm{N}=5)\end{array}$ & $\begin{array}{c}\text { Non Smoker } \\
(\mathrm{N}=25)\end{array}$ & $\begin{array}{c}\text { Smoker } \\
(\mathrm{N}=21)\end{array}$ & $\begin{array}{c}\text { Non Smoker } \\
(\mathrm{N}=11)\end{array}$ \\
\hline BMl $(\mathrm{Kg} / \mathrm{m} 2)$ & $23.48 \pm 4.24$ & $23.68 \pm 3.97$ & $24.63 \pm 3.85$ & $26.21 \pm 3.49$ \\
W/H & $0.91 \pm 0.07$ & $0.94 \pm 0.09$ & $0.98 \pm 0.07$ & $0.94 \pm 0.06$ \\
TC $(\mathrm{mg} / \mathrm{dl})$ & $152 \pm 11$ & $155 \pm 26$ & $184 \pm 38$ & $185 \pm 36$ \\
TG $(\mathrm{mg} / \mathrm{dl})$ & $129 \pm 58$ & $121 \pm 31$ & $169 \pm 96$ & $168 \pm 28$ \\
HDL $(\mathrm{mg} / \mathrm{dl})$ & $40 \pm 4$ & $45 \pm 8$ & $44 \pm 7$ & $41 \pm 5$ \\
VLDL $(\mathrm{mg} / \mathrm{dl})$ & $26 \pm 11$ & $24 \pm 6$ & $33 \pm 19$ & $35 \pm 15$ \\
LDL $(\mathrm{mg} / \mathrm{dl})$ & $86 \pm 9$ & $85 \pm 21$ & $105 \pm 29$ & $109 \pm 35$ \\
STAA $(\mu \mathrm{mol} / \mathrm{l})$ & $694 \pm 126$ & $732 \pm 212$ & $656 \pm 172$ & $686 \pm 186$ \\
PTBARS $(\mathrm{nmol} / \mathrm{ml})$ & $2.27 \pm 0.54$ & $2.44 \pm 0.63$ & $3.47 \pm 0.82$ & $2.94 \pm 0.75$ \\
UTBARS $(\mathrm{nmol} / \mathrm{ml})$ & $2.67 \pm 1.49$ & $4.07 \pm 1.58$ & $4.25 \pm 1.62$ & $4.60+2.44$ \\
\hline
\end{tabular}

Independent sample-t test: $p<0.05=a, p<0.01=b$ and $p<0.001=c$

We would specifically like to mention about PTBARS. It showed a progressive rise with age. The relationship between ages versus PTBARS was ascertained by correlation coefficient and was found out to be 0.473 (p-0.008) which is highly significant. These observations were highly interesting. Ever since Harman (1956) hypothesized the free radical driven aging wheel $^{7}$, various theories have gyrated till Beckman and Ames (1998) consolidated them to title "The free radical theory of aging matures". ${ }^{25}$ Recently Gil et al (2006) examined MDA, protein carbonyls, 4-hydroxy-2, 3-transnomeal, reduced glutathione, glutathione disulfide and uric acid in and plasma samples of 194 healthy women and men of ages ranging from 18 to 84 years and concluded that the balance of oxidant and antioxidant systems in plasma shifts in favor of accelerated aging. ${ }^{26}$ In HTN patients, Age Vs PTBARS did not provide discernible trend. This may be expected because the disease processes are multifactorial and have cumulative influence on the disease process.

Plasma and urinary MDA were significantly increased in smoker than non-smokers and also alcohol consumption is involved in causing oxidative stress. ${ }^{27,28}$ In Nepal, 
smoking is very common and still more common is the accompanying habit of drinking. Thus, in the present study, we have examined the effect of smoking and drinking category viz: smoker and non-smoker and alcoholics and non-alcoholics in normal subjects and HTN patients (Table 4,5). We could not find its significant role in oxidative stress, antioxidant status and lipid profile. Our result of oxidative stress is comparable to the study conducted in Pokhara by Jha JC et al where they did not find increased oxidative stress in healthy smokers. ${ }^{29}$ Thus, our observation indicated that smoking and drinking have no role in lipid profile derangement, increased oxidative stress and fall in total TAA in both the control and HTN patients.

Obesity is closely associated with metabolic syndrome includinghyperglycemia, dyslipidemiaandhypertension. ${ }^{30}$ The study done by Keaney et al also showed significant positive correlation between OS and BMI. ${ }^{31}$ Contrary to this, our study did not show such association (Table 3 ). Of late, waist circumference and waist-hip ratio $(\mathrm{W} / \mathrm{H})$ are projected as a better predictive index than BMI for CVD, Wildman, et al, (2005) have concluded it in the Chinese population and have suggested these conclusions should be examined in other racial populations. ${ }^{32}$ In our population, both $\mathrm{BMI}$ and $\mathrm{W} / \mathrm{H}$ are not increased significantly in HTN patients (Table 1).

Oxidised LDL aggravates hypertension. ${ }^{33}$ It has been shown that increasing plasma TBARS level increases oxidized LDL level and oxidized LDL enhances atheroscelerosis. ${ }^{11,34}$ Therefore, with our result of significant raised plasma TBARS and lipid profile in hypertensive patients, we can assume that oxidized LDL did increase in HTN patients of our study which could have aggravated hypertension and enhanced atherosclerosis. However, further research is necessary to elucidate this phenomenon in our population.

\section{CONCLUSION}

Accounting all the data together, we can conclude from our observations that lipid profile is unfavorably altered in HTN and oxidative stress is significantly raised. Dyslipedemia and raised oxidative stress are the established risk factors for the atheroscelerosis. Therefore, our study indicates that monitoring of the lipid level and maintaining of the oxidative balance in hypertensive patients would be helpful in preventing the CVD and other diseases associated with hypertension.

\section{REFERENCE}

1. Kearney PK, Whelton M, Reynolds K, Muntner P, Whelton PK, Jiang H. Global burden of hypertension: analysis of worldwide data. Lancet 2005;365:217-23.

2. Park K. Park's textbook of Preventive and Social Medicine. 17th ed. Jabalpur (India): M/s Banarsidas Bhanot publishers; 2002. p. 274-5.

3. WHO. Health situation in South East Asia Regions. Geneva: 2002.

4. Baral N, Jha P, Sridhar MG, Karki P, Sharma SK, Khambu B. Association of lipid profile and body mass index (bmi) in Hypertensive patients of Eastern Nepal. JNMA 2006; 45:306-9.

5. Lassegue B, Griendling KK. Reactive Oxygen Species in Hypertension- Review. Am J of Hypertention 2004; 17:852-60.

6. Halliwell B. Free radicals, antioxidants and human disease: curiosity, cause, or consequences? Lancet 1994;344:721-4.

7. Harmann D. Aging: a theory based on free radical and radiation chemistry. J Gerontol 1956;11:298-300.

8. Cohen RA, Zitnay KM, Haudenschild CC, Cunningham LD. Loss of selective endothelial cell vasoactive functions caused by hypercholesterolemia in pig coronary arteries. Cir Res 1988;63:903-910.

9. Chin JH, Azhar S, Hoffman BB. Inactivation of endothelial derived relaxing factor by oxidized lipoprotein. J Clin Invest. 1992;89:1018 .

10. Tamai O, Matsuoka H, Itabe H, WadaY, Kohno K, ImaizumiT. Single LDL apheresis improves endothelium-dependent vasodilatation in hypercholesterolemic humans. Circulation. 1997 Jan 7;95(1):7682 .

11. Navab M, Berliner JA, Watson AD, Hama SY, Territo MC, Lusis AJ, et al. The Yin and Yang of oxidation in the development of the fatty streak. A review based on the 1994 George Lyman Duff Memorial Lecture. Arterioscler Thromb Vasc Biol 1996;16:831-42.

12. Madamanchi NR, Vendrov A, Runge MS. Oxidative Stress and Vascular Disease. Arterioscler Thromb Vasc Biol. 2005;25:29-38.

13. Grundy SM, Brewer HB Jr, Cleeman JI, Smith SC Jr, Lenfant C; American Heart Association; National Heart, Lung, and Blood Institute. Definition of metabolic syndrome: Report of the National Heart, Lung, and Blood Institute/American Heart Association conference on scientific issues related to definition. Circulation. 2004 Jan 27;109(3):433-8.

14. Shigetada F, Takuya F, Michio, Masanori I, Yukio Y, Yoshimitsu $\mathrm{N}$, et al. Increased oxidative stress in obesity and its impact on metabolic syndrome. The Journal of Clinical Investigation 2004;114(12):1752-61.

15. Benzie IF and Starin JJ. The ferric reducing ability of plasma (FRAP) as a measure of "antioxidant power": The FRAP assay. Annal Biochem 1996;239:70-76.

16. Buege JA, Aust SD. The Thiobarbituric Acid assay. Method in enzymology 1978;52:306-10.

17. Siedel J, Hagele EO, Ziegenhorn J, Wahlefeld AW. Reagent for the enzymatic determination of serum total cholesterol with improved lipolytic efficiency. Clin Chem 1983;20:1075.

18. Mc Gowan MW, Artiss JD and Zak BA. Peroxidase coupled method for the colorimetric determination of serum triglycerides. Clin Chem 1983;29:538. 
19. FriedwaldWT, Levy RI, Fredricson DS. Estimation of concentration of low-density lipoprotein in plasma, without use of preparative ultracentrifuge. Clin Chem 1972;18: 499-502.

20. Ghafoorunissa, Krishnaswamy K. Diet and Heart Disease. Hydrabad: ICMR Publication; 1994. p. 10-8.

21. Kasper DL, Fauci AS, Longo DL, Braunwald E, Hauser SL, Jameron JL editors. Harrison's Principle of Internal Medicine. $16^{\text {th }}$ ed. New York: McGraw Hill Publishing division; 2005. p. 2152-82.

22. Tiwari AK. Antioxidants: New-generation therapeutic base for treatment of polygenic disorder. Curr Sci 2004;86(8):192-212.

23. Singh PP, Gupta S. Oxidative stress as a risk factor on CVD. In: Singh PP, Mamatha GP, editors. Antioxidants and trace elements in medicine and Dentistry. 2006. p. 66.

24. Blomhoff R. Dietary antioxidant and cardiovascular disease. Curr Opi Lipi 2005;16(1): 47-54

25. Beckman KB, Ames BN. The free radical theory of aging matures. Physiol. Rev 1998;78: 547-81.

26. Gil L, Siems W, Mazurek B, Johann G, Schroeder, Voss P, Grune T. Age-associated analysis of oxidative stress parameters in human plasma and erythrocytes. Free Radical Journal 2006;40;495-505.

27. Agarwal R. Smoking, oxidative stress and inflammation: impact on resting energy expenditure in diabetic nephropathy. BMC Nephrology 2005; 6:13-7.

28. Bailey SM, Cunninghams CC. Contribution of mitochondria to oxidative stress associated with alcoholic liver disease. Free Radical Biology \& Medicine 2002;32:11-6.
29. Jha JC, Maharjan BR, Adhikari D, Vishwanatha P, Akila, NagammaT, et al. Cigarette smoke induced oxidative insult in local population of Pokhara. Kath Univ Med J 2007;5:511-17.

30. Grundy SM, Brewer HB Jr, Cleeman JI, Smith SC Jr, Lenfant C; American Heart Association; National Heart, Lung, and Blood Institute. Definition of metabolic syndrome: Report of the National Heart, Lung, and Blood Institute/American Heart Association conference on scientific issues related to definition. Circulation. 2004 Jan 27;109(3):433-8.

31. Keaney JF, Larson MG, Vasan RS, Wilson PWF, Lipinska I, Corey D, et al. Obesity and Systemic Oxidative Stress: Clinical Correlates of Oxidative Stress in The Framingham Study. Arterioscler Thromb Vasc Biol 2003;23:434-39.

32. Wildman RP, Gu D, Reynolds K, Duan X, Wu X and He J. Are waist circumference and body mass index independently associated with cardiovascular disease risk in Chinese adults? Am J Clin Nutr 2005;82:1195-202.

33. Chin JH, Azhar S, Hoffman BB. Inactivation of endothelial derived relaxing factor by oxidized lipoprotein. J Clin Invest. 1992;89:1018.

34. Bielicki JK, Forte TM, McCall MR. Minimally oxidized LDL is a potent inhibitor of lecithin:cholesterol acyltransferase activity. J Lipid Res. 1996 May;37(5):1012-21. 